\title{
Randomised double blind placebo controlled trial of prednisolone in children admitted to hospital with respiratory syncytial virus bronchiolitis
}

Job B M van Woensel, Tom F W Wolfs, Wim M C van Aalderen, Paul L P Brand, Jan L L Kimpen

\begin{abstract}
Background - Experimental and clinical evidence suggests that respiratory syncytial virus (RSV) bronchiolitis is an immune mediated disease. Corticosteroids might therefore be effective in the treatment of RSV bronchiolitis.

Methods - A randomised double blind trial was conducted in children up to two years of age admitted to hospital with RSV bronchiolitis to compare prednisolone $(1 \mathrm{mg} /$ kg/day orally for seven days) with placebo. Variables used for the efficacy analysis were a daily symptom score and the length of time in hospital in the non-ventilated patients, and the duration of mechanical ventilation and the length of time in hospital in the ventilated patients.

Results - Fifty four patients were included in the trial, 40 of whom were non-ventilated (20 in each group) and 14 were ventilated (seven in each group). During the first three days of treatment the symptom score decreased significantly faster in the prednisolone group than in the placebo group (mean (SE) decrease $-1.2(0.2)$ points/day versus $-0.6(0.2)$ points/day; mean $(95 \%$ confidence interval $(\mathrm{CI}))$ for difference $=-0.6(-0.1$ to -1.2$) ; p=0.02)$. The mean duration of hospital stay of all 40 non-ventilated patients was not significantly different between the two groups. In the ventilated patients the duration of mechanical ventilation was not significantly different, but the length of time in hospital was six days shorter in the prednisolone group than in the placebo group (mean (SE) $11.0(0.7)$ versus 17.0 (2.0) days; mean $(95 \% \mathrm{CI})$ difference $=7.0$ (1.8 to 10.2$)$ days; $p<0.01$ ).

Conclusions - These results suggest that prednisolone may be effective in accelerating the clinical recovery of children admitted to hospital with RSV bronchiolitis.
\end{abstract}

(Thorax 1997;52:634-637)

Keywords: respiratory syncytial virus, bronchiolitis, corticosteroids, treatment.

Respiratory syncytial virus (RSV) is the most important cause of viral bronchiolitis in young children. ${ }^{1}$ Moreover, RSV is the causative pathogen in most children admitted to hospital with lower respiratory tract infections in the winter. $^{2}$ Although the pathogenesis of RSV bronchiolitis is not fully understood, increasing experimental evidence suggests that the host immune response plays an important role. ${ }^{23}$ In addition, both pathological and clinical analogy exists between RSV bronchiolitis and childhood asthma. Similar cell types are involved, ${ }^{4-6}$ and RSV bronchiolitis is frequently followed by recurrent episodes of wheezing later in childhood. ${ }^{78}$ Based on the immunopathogenesis of RSV bronchiolitis and its analogy with asthma, corticosteroids might theoretically be a therapeutic option. The effect of corticosteroids in children with bronchiolitis has been studied previously, but results of these studies are inconsistent. ${ }^{9-16}$ Most studies were not confined to patients with microbiologically confirmed RSV bronchiolitis. ${ }^{9-1113}$ One study demonstrated no effect of corticosteroids in confirmed RSV cases. However, patients at risk for severe disease were excluded. ${ }^{12}$ To determine the effect of prednisolone on the clinical course of children admitted to hospital with RSV bronchiolitis, including patients with severe disease, we conducted a prospective randomised double blind placebo controlled trial.

\section{Methods}

STUDY POPULATION

All children younger than two years with microbiologically confirmed RSV bronchiolitis admitted to the Beatrix Children's Hospital between December 1992 and April 1995 were included after written informed consent was obtained from parents or caretakers. Bronchiolitis was defined as acute tachypnoea, wheezing and/or decreased breath sounds, cyanosis and the use of accessory respiratory muscles, in the presence of an apparent viral infection. RSV infection was confirmed by direct immunofluorescence assay using fluorescein isothiocyanate (FITC)-labelled monoclonal antibodies of Imagen (Novo Nordisk Diagnostics Ltd, Cambridge, UK). Patients who had used corticosteroids (systemic or by inhalation) during the two months before admission were excluded. The study was approved by the medical ethics committee of the hospital.

\section{STUDY DESIGN}

Patients were randomly allocated to the treatment or placebo groups by the hospital phar- 
Table 1 Characteristics of the patients at entry to the study

\begin{tabular}{lll}
\hline & Prednisolone $(n=27)$ & Placebo $(n=27)$ \\
\hline Median (IQR) age (months) & $3.3(1.4-5.9)$ & $3.9(1.9-6.1)$ \\
Sex (F:M) & $9: 18$ & $16: 11$ \\
Family history of atopy & 9 & 10 \\
Risk group* & 6 & 9 \\
Mean (SD) log IgE & $0.7(0.3)$ & $1.1(0.7)$ \\
Median (IQR) symptom score & $5.5(4.0-7.0)$ & $5.5(3.5-7.0)$ \\
\hline
\end{tabular}

* Risk group = patients with congenital heart disease, bronchopulmonary dysplasia, or ex-premature patients. macy using blinded sealed envelopes, the sequence of which was determined by random number tables. Patients were stratified into groups according to their weight $(3-5 \mathrm{~kg}$, $5-7 \mathrm{~kg}$, etc). The study treatment was oral prednisolone powder $(1 \mathrm{mg} / \mathrm{kg} /$ day in two divided doses for seven days) or placebo, delivered as identical capsules, which were broken and dissolved in water. Treatment was started within 24 hours of admission. If a patient vomited within 60 minutes after intake, a repeat dose was given. The decision to treat patients with supplemental oxygen, bronchodilators, or antibiotics, or to discharge them, was at the discretion of the attending physician, independent of the investigators.

\section{EFFICACY ANALYSIS}

For the efficacy analysis patients were divided into two groups depending on whether or not they were on mechanical ventilation at the time of entry into the study. In the non-ventilated patients a daily recorded standardised symptom score, as described previously, ${ }^{10}$ and the duration of the stay in hospital were used as outcome variables. The symptom score evaluated four items: respiratory rate, presence of wheezing, presence of cyanosis, and the use of accessory respiratory muscles. Each of these items was scored on an ordinal scale from 0 (normal or none) to 3 (severe). The symptom score therefore ranged from 0 (no symptoms) to 12 (severe bronchiolitis). Patients were scored when quietly awake and at the same time of day. Only two investigators performed the scoring (JBMvW, TFWW) and each patient was scored throughout the study by the same investigator. For each patient the symptom score was plotted against time. The slope of the regression line through these points, representing the mean daily decrease in the symptom score (points/ day), was used in the statistical analysis. ${ }^{17} \mathrm{Clin}-$ ical experience had shown that most children with acute bronchiolitis have recovered after seven days so that a difference in symptom scores between treatment groups by that day would no longer be discernible. We hypothesised before the study that the largest difference, if any, between treatment groups would be observed half way between the start of the study (day 0) and full recovery (day 7) - that is, on day 3. It was felt that a difference of at least one point in the clinical score between groups on day 3 would be clinically relevant. Using a power calculation, estimating the SD of the symptom score to be 1 , and wishing to detect a difference in symptom scores between groups of 1 , with $90 \%$ power and the type I

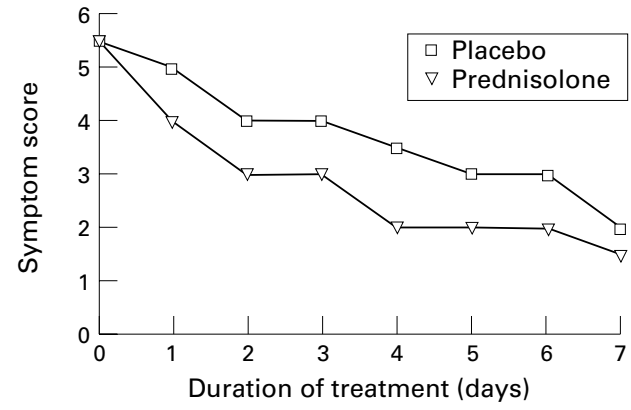

Figure 1 Median symptom scores for all non-ventilated patients (20 in the prednisolone group and 20 on placebo on day 0).

error $(\alpha)$ set at 0.05 , the required study population of non-ventilated patients was 20 evaluable patients in each group. ${ }^{18}$

In the ventilated patients duration of mechanical ventilation and duration of hospital stay were used to evaluate efficacy.

STATISTICAL ANALYSIS

Statistical analyses were performed with the SPSS/PC + package, version 5.0.2. (SPSS Inc). For normally distributed data the Student's $t$ test was used to compare group means, otherwise the Mann-Whitney U test was applied. Proportions were compared by the $\chi^{2}$ test. Values are expressed as mean (SE) unless stated otherwise. A two sided $p$ value of $<0.05$ was considered statistically significant.

\section{Results}

During three seasons 54 children were enrolled into the study of which 27 were randomised to receive prednisolone and 27 placebo. The characteristics of the patients at entry to the study did not differ significantly between the two groups (table 1 ).

Forty patients (20 in each group) were not on mechanical ventilation at entry to the study. Two of these (both on placebo) needed mechanical ventilation after the start of the study medication, one patient after one day and the other after three days. Since change over three days in non-ventilated patients was the intended end point of our study, the first patient was omitted from the efficacy analysis.

The course of the symptom score of the remaining 39 non-ventilated patients is shown in fig 1 . During the first three days of treatment the symptom score decreased significantly faster in the prednisolone group $(-1.2(0.2)$ points/day) than it did in the placebo group $(-0.6(0.2)$ points/day; $95 \%$ confidence interval (CI) for difference $=-1.2$ to $-0.1, \mathrm{p}=$ $0.02)$. The length of time in hospital was one day shorter in the prednisolone group than in the placebo group; this difference was not significant (7.3 (1.2) versus 8.3 (0.9) days, respectively, $95 \% \mathrm{CI}$ for difference $=-4.1$ to $2.2, \mathrm{p}=0.54)$. We observed a trend towards greater treatment benefit in patients with more severe bronchiolitis (symptom score $>6$ at entry): the mean decrease of the symptom 
score in the first 3 days of treatment was -1.8 $(0.2)$ points/day in the prednisolone group and $-0.8(0.3)$ points/day in the placebo group. In order to determine whether the effect of treatment was dependent on the severity of symptoms at entry we performed an analysis of variance modelling the effects of treatment, baseline severity score, and the interaction between the two. Only treatment entered the model significantly $(\mathrm{F}=4.96, \mathrm{p}=0.03)$, whereas neither baseline severity score $(\mathrm{F}=$ 1.03, $\mathrm{p}=0.31)$ nor the interaction term $(\mathrm{F}=$ $0.06, \mathrm{p}=0.81$ ) contributed significantly.

Fourteen patients (seven in each group) were on mechanical ventilation at entry into the study. One girl with bronchopulmonary dysplasia died three weeks after admission as a result of respiratory failure. She had received placebo. The duration of mechanical ventilation was 1.6 days shorter in the prednisolone group (4.7 (1.1) days) than in the placebo group (6.3 (1.6) days), 95\% CI for difference $=$ -5.8 to $2.7, \mathrm{p}=0.56$. None of the patients in either group needed to be re-intubated due to upper respiratory tract symptoms resulting from intubation. The duration of stay in hospital was six days shorter in the prednisolone group (11.0 (0.7) days) than in the placebo group (17.0 (2.0) days), 95\% CI for difference $=-10.2$ to $-1.8, \mathrm{p}<0.01$.

Neither a positive family history for atopic disease nor the total IgE level of the patients at entry to the study confounded the effect of prednisolone. There was no significant difference in the duration of supplemental oxygen, the use of bronchodilators, or the proportion of patients who received antibiotics between the two groups.

\section{Discussion}

The results of this study suggest that systemic corticosteroids may be effective in accelerating the clinical recovery of children admitted to hospital with RSV bronchiolitis. Patients who were treated with prednisolone showed a significantly faster clinical improvement, although the beneficial effect of prednisolone was relatively small. Ventilated patients who were treated with prednisolone were admitted to hospital for a considerably shorter duration than patients in the placebo group.

Several investigators have studied the effect of corticosteroids in children with bronchiolitis, but results are inconsistent. ${ }^{9-14}$ Studies that demonstrated a beneficial effect had an inhomogeneous study population ${ }^{10}$ or numbers were small. ${ }^{1014}$ Three other studies could not demonstrate a beneficial effect of corticosteroids on bronchiolitis, although none of these studies was confined to patients with microbiologically confirmed RSV bronchiolitis. $^{911131516}$ This may partly explain the differences from the results of the present study and stresses the importance of strict inclusion criteria. We included only patients with RSV induced wheeze.

RSV causes most but not all cases of bronchiolitis $^{2}$ and the inflammatory response to other pathogens may differ from that observed to RSV - that is, interferon is found in significantly lower amounts in the nasopharynx of children with RSV infections than in children with parainfluenza or influenza virus infections. ${ }^{1920}$ Recently, De Boeck et al demonstrated no effect of corticosteroids on microbiologically confirmed RSV bronchiolitis. ${ }^{12}$ In this study, however, patients belonging to risk groups for severe RSV bronchiolitis were excluded because of alternative treatment. In our study there was a trend towards a greater beneficial effect of steroid therapy in more severely affected children. This trend, however, was not statistically significant. In addition, our study was not specifically designed to answer this question. The observed trend would suggest that additional studies on the effect of steroid treatment in infants with severe RSV bronchiolitis are warranted.

RSV alone is not sufficient to cause disease, and increasing evidence suggests that the immune response to RSV leading to airway inflammation contributes considerably to illness..$^{2-521-23}$ Corticosteroids may reduce this airway inflammation. ${ }^{24}$ Airway inflammation in children is difficult to study. The symptom score that we and others used is obviously an insensitive method for assessing improvement in lung function. In children with a low pretreatment score the symptom score is especially less sensitive than in children with a higher pretreatment score.

Further study should focus on more sensitive measurements of airway inflammation, such as cell or cytokine profiles in bronchoalveolar lavage fluid, to measure more directly the effect of corticosteroids.

The beneficial effects of corticosteroids should be weighed against their side effects. In the present study no clinical significant side effects of prednisolone were found. This is in accordance with previous studies regarding the safety of short courses of oral steroids for asthma exacerbations and croup in children. ${ }^{25-27}$ Viral shedding may be prolonged by corticosteroids ${ }^{28}$ However, the clinical and epidemiological consequences of a possible prolonged period of viral shedding in the limited group of patients who need to be admitted to hospital with severe RSV bronchiolitis are probably small.

In conclusion, this study shows that prednisolone is effective in accelerating the clinical recovery of children admitted to hospital with RSV bronchiolitis. The effect is limited and more studies are required to evaluate the role of steroid therapy in these infants.

This study was supported by a grant from the Stichting Astmabestrijding, Bussum, The Netherlands.

1 Glezen WP, Denny FW. Epidemiology of acute lower respiratory disease in children. $N$ Engl $\mathcal{f}$ Med 1973;288. piratory

2 Ruuskanen O, Ogra PL. Respiratory syncytial virus. Curr Probl Pediatr 1993;23:50-79.

3 Kimpen JLL, Heymans HSA. Respiratory syncytial virus: immunity and immune injury. Immunol Infect Dis 1993;3 $281-8$

4 Graham BS, Bunton LA, Wright PF, Karzon DT. Role of $T$ lymphocyte subsets in the pathogenesis of primary infection and rechallenge with respiratory syncytial virus in mice. F Clin Invest 1991;88:1026-33.

5 Garofalo R, Kimpen JLL, Welliver RC, Ogra PL. Eosinophil degranulation in the respiratory tract during naturally 
acquired respiratory syncytial virus infection. $\mathcal{f}$ Pediatr 1992;120:28-32

6 Welliver RC, Tej TN, Ogra PL. The appearance of cellbound IgE in respiratory tract epithelium after respiratory syncytial virus infection. $N$ Engl f Med 1980;303:1198202 .

7 Sigurs N, Bjarnason R, Sigurbergsson F, Kjellman B, Bjorksten $\mathrm{B}$. Asthma and immunoglobulin $\mathrm{E}$ antibodies after respiratory syncytial virus bronchiolitis: a prospective cohort study with matched controls. Pediatrics 1995;95: 500-7.

8 Pullan CR, Hey EN. Wheezing, asthma and pulmonary dysfunction 10 years after infection with respiratory syncytial virus in infancy. BMf 1982;284:16659.

9 Springer C, Bar-Yishay E, Uwayyed K, Avital A, Vilozni D, Godfrey S. Corticosteroids do not affect the clinical or physiological status of infants with bronchiolitis. Pediatr physiological status of infa

10 Tal A, Bavilski C, Yohai D, Bearman JE, Gorodischer $\mathrm{R}$, Moses SW. Dexamethasone and salbutamol in the
treatment of acute wheezing in infants. Pediatrics 1983; treatmen

11 Leer JA, Green JL, Heimlich EM, Hyde JS, Moffet HL, Young GA, et al. Corticosteroid treatment in bronchiolitis. Am f Dis Child 1969;117:495-503.

12 De Boeck K, Van der Aa N, Van Lierde S, Corbeel L, Eeckels R. Respiratory syncytial virus bronchiolitis. A double blind dexamethasone efficacy study. Am F Respir Crit Care Med 1994;149:A345.

13 Dabbous IA, Tkachyk JS, Stamm SJ. A double blind study on the effects of corticosteroids in the treatment of bronchiolitis. Pediatrics 1966;37:477-84.

14 Oski FA, Salitsky S, Barness LA. Steroid therapy in bronchiolitis: a double-blind study. Am F Dis Child 1961;102: 759 .

15 Connolly JH, Field CMB, Glasgow JTF, Slattery CM, MacLynn DM. A double blind trial of prednisolone in epidemic bronchiolitis due to respiratory syncytial virus. Acta Paediatr Scand 1969;58:116-20.

16 Sussman S, Grossman M, Magofinn R, Shielbe J. Dexamethasone in obstructive respiratory tract infection in children: a controlled study. Pediatrics 1964;34:851.
17 Matthews JNS, Altman DG, Campbell MJ, Royston P. Analysis of serial measurements in medical research. $B M F$ 1990;300:230-5.

18 Armitage P, Berry G. Statistical methods in medical research. 3rd ed. Oxford: Blackwell Scientific Publications, 1994 195-204.

$19 \mathrm{McIntosh} \mathrm{K}$. Interferon in nasal secretions from infants with viral respiratory tract infections. 7 Pediatr 1978;93:33-6.

20 Hall CB, Douglas RG, Simons RL, Geiman JM. Interferon production in children with respiratory syncytial, in-
fluenza, and parainfluenza virus infections. F Pediatr 1978; 93:28-32.

21 Anderson LJ, Tsou C, Potter C, Keyserling HL, Smith $\mathrm{TF}$, Ananaba $\mathrm{G}$, et al. Cytokine response to respiratory TF, Ananaba $\mathrm{G}$, et al. Cytokine response to respiratory syncytial virus stimulation of human peripheral
mononuclear cells. F Infect Dis 1994;1 170:1201-8.

22 Midulla F, Villani A, Panuska JR, Dab I, Kolls JK, Merolla $\mathrm{R}$, et al. Respiratory syncytial virus lung infection in infants: immunoregulatory role of infected alveolar macrophages. F Infect Dis 1993;168:1515-9.

23 Wong DT, Rosenband M, Hovey K, Ogra PL. Respiratory syncytial virus infection in immunocompromised animals: implications in human infection. F Med Virol 1985;17: 359-70.

24 Schleimer RP. Effects of glucocorticosteroids on inflammatory cells relevant to their therapeutic applications in asthma. Am Rev Respir Dis 1990;141:s59-69.

25 Scarfone RJ, Fuchs SM, Nager AL, Shane SA. Controlled trial of oral prednisolone in emergency department treatment of children with in emergency department treatment of

26 Tibballs J, Shann FA, Landau LI. Placebo-controlled trial of prednisolone in children intubated for croup. Lance 1992;340:745-8.

27 Rubin BK, Marcushamer S, Priel I, App EM. Emergency management of the child with asthma. Pediatr Pulmonol 1990;8:45-7.

28 Hall CB, Powell KR, MacDonald NE, Gala CL, Menegus $\mathrm{ME}$, Suffin SC, et al. Respiratory syncytial virus infection in children with compromised immune function. $N$ Engl f Med 1986;315:77-81. 